\title{
The illicit sale of prescribed opioid medications in Edmonton, Alberta
}

\author{
Darcy Strang ${ }^{1}$, Saifee Rashiq MB FRCPC²
}

$\mathrm{T}$ he effective treatment of pain is a growing medical and societal priority. The most appropriate and effective tools for this purpose, in many specific circumstances, are opioid analgesics, but the abuse of opioids is a problem with enormous social consequences.

While all physicians recognize the existence of this problem, few are well informed about the specifics of the street drug trade in their own locales. Excellent descriptive studies of street drug pricing and availability have sought to decrease the error of price estimates by obtaining data from many traders (1), but in the end, these studies rely necessarily on descriptions of prices paid rather than witnessing the actual transactions. They are also difficult and hazardous to conduct. One would also expect the street drug trade to vary in character from place to place.

We combined our respective viewpoints to offer this narrative description of the street drug trade in Edmonton, Alberta in 2005 and some possible explanations of its characteristics. Darcy Strang is an undercover law-enforcement officer, specializing in narcotics, who buys illicit narcotics from street dealers on a daily basis.

Narcotics intended for therapeutic use are plentiful on the streets of Edmonton. Edmonton has a very small heroin-using community and prescription opioids have filled the void. Prescription drugs, although not as common as cocaine or methamphetamine, are a frequent choice of the street drug user; they are procured by robbery, diversion, the sale of legally obtained prescriptions and the use of stolen prescription blanks. Compared with methamphetamine users, opioid users are characteristically older and more experienced drug users. Many methamphetamine addicts use opioids (or benzodiazepines or other sedatives) to control the symptoms of methamphetamine withdrawal.

Injection of crushed pills is mostly concentrated in the inner city but certainly not limited to this area. The downtown area seems to always have one or two establishments that specialize in the sale of illicit pills. Law enforcement efforts to address these community problems often merely result in moving the problem to another bar or cafe. It is also difficult for police to charge individuals for possession or possession for the purpose of trafficking these substances, because the possession of opioids is not always illegal. Case law does not wholly support the aforementioned offences when prescription pills are found.

The major market is in products that are familiar and easy to recognize. Brand names are preferred. Prices are mostly stable over time and are linked to the potency of the product. Thus, a $100 \mathrm{mg}$ MS Contin tablet (Purdue Pharma, Canada), the most popular strength because of its ease of acquisition, retails for $\$ 20$, and a $200 \mathrm{mg}$ tablet sells for exactly double the price of the $100 \mathrm{mg}$ tablet. A $60 \mathrm{mg}$ tablet is worth $\$ 10$, but the weaker strengths are rarely seen. These pills are crushed, dissolved and injected.

Dilaudid (hydromorphone) tablets (Abbott Laboratories, Canada) are also crushed and injected, but they command a higher relative price. A 2 mg Dilaudid tablet, for example, sells for $\$ 10$. Allowing for a potency ratio between morphine and hydromorphone of 1:5, the purchaser would be getting much less opioid for his $\$ 10$ outlay by purchasing this instead of a $60 \mathrm{mg}$ MS Contin pill, suggesting that the Dilaudid offers some other attraction to the user. The higher strengths of Dilaudid, $4 \mathrm{mg}$ and $8 \mathrm{mg}$, are more popular and sell for $\$ 20$ and $\$ 30$, respectively. Controlled-release hydromorphone preparations can be taken orally but are usually injected.

All oxycodone preparations are more likely to be taken orally than injected. This may reflect recognition of oxycodone's higher bioavailability than other opioids. OxyContin (Purdue Pharma), a long-acting oxycodone preparation, is most often chewed and swallowed (although it is sometimes melted for injection). At $\$ 25$ to $\$ 30$ for $80 \mathrm{mg}$, it is the least cost-effective offering.

A variety of products are offered to the low-budget user. Tylenol \#3 and \#4 (Janssen-Ortho/McNeil Consumer Healthcare, USA) tablets sell for $\$ 0.50$ and $\$ 1$, respectively, reflecting the relative amount of opioid in each. This represents a steep premium over the morphine products, particularly if the codeine is taken orally, because of its low bioavailability. Tylenol \#4 and alcohol is a commonly used combination among street users.

\footnotetext{
${ }^{1}$ Drug Unit, Organized Crime Branch, Edmonton Police Service; ${ }^{2}$ Multidisciplinary Pain Centre, University of Alberta Hospitals, Edmonton, Alberta

Correspondence: Dr Saifee Rashiq, Multidisciplinary Pain Centre, University of Alberta Hospitals, \#8 - 120 Clinical Sciences Building, Edmonton, Alberta T6G 2G3. Telephone 780-407-8896, fax 780-407-3200, e-mail SRashiq@ualberta.ca
} 
Nonopioids are also traded and the penalties for trafficking non-narcotic agents are much lower than those for opioids. Common sentences levied by the courts for the trafficking of ounces of cocaine and methamphetamine are much lower than the sentences for the trafficking of opioids; the sentencing guideline for an individual with no criminal record who has trafficked in opioids begins at two years' imprisonment, whereas traffickers of whole ounces of cocaine and methamphetamine are routinely given less than six months or even conditional sentence orders (no incarceration or fine). A $5 \mathrm{mg}$ tablet of Valium (Roche, USA) sells for $\$ 1$ and $5 \mathrm{mg}$ Ritalin (Novartis Pharmaceuticals Canada Inc) for $\$ 10$.

Preparations less commonly sold for abuse are methadone and fentanyl. This simply reflects a lack of familiarity with these drugs.

We concur with others who suggest that current approaches to preventing the illicit sale of narcotics are proving to be of limited effect (2). Physicians should be aware that, in general, almost any type of narcotic or sedative may be sold, even if it requires a triplicate prescription. Because the diversion of properly issued or filled prescriptions is only one of many ways for these drugs to reach the street, changing individual prescribing patterns is unlikely to provide a complete solution and may only serve to deprive suffering patients of proper treatment. From time to time, certain specific opioid preparations may command little or no street value and may, therefore, be better prescription choices, but this is a fluid circumstance. Careful attention to the security of prescribing and dispensing resources and regular discussion of the issue with law-enforcement professionals would seem to be the best approaches by doctors to this ongoing problem.

\section{REFERENCES}

1. Sajan A, Corneil T, Grzybowski S. The street value of prescription drugs. CMAJ 1998;159:139-42.

2. Shepard EM, Blackley PR. Drug enforcement and crime: Recent evidence from New York State. Soc Sci Q 2005;86:323-42. 


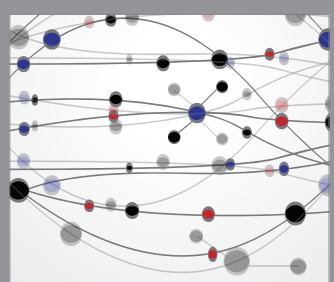

The Scientific World Journal
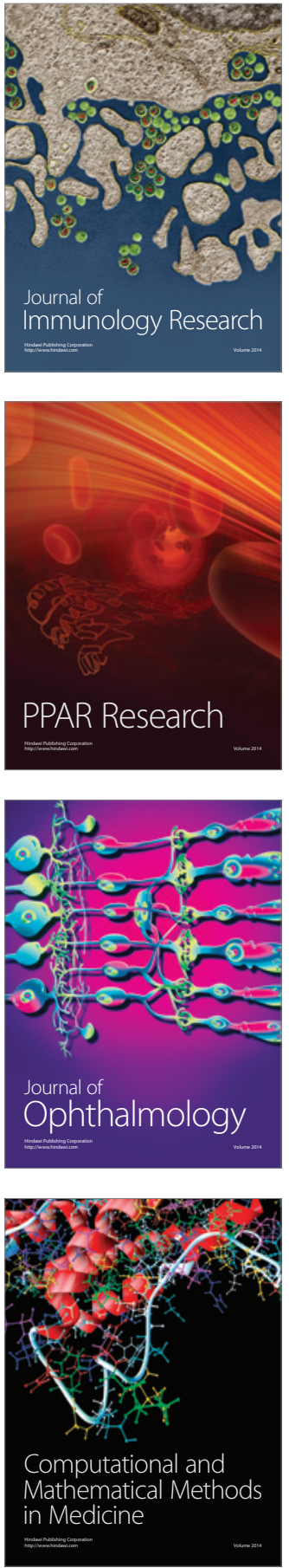

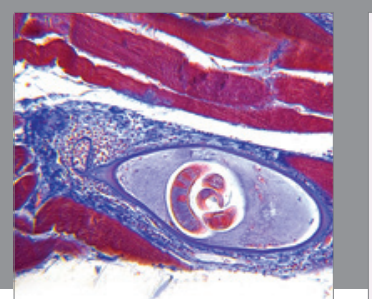

Gastroenterology Research and Practice

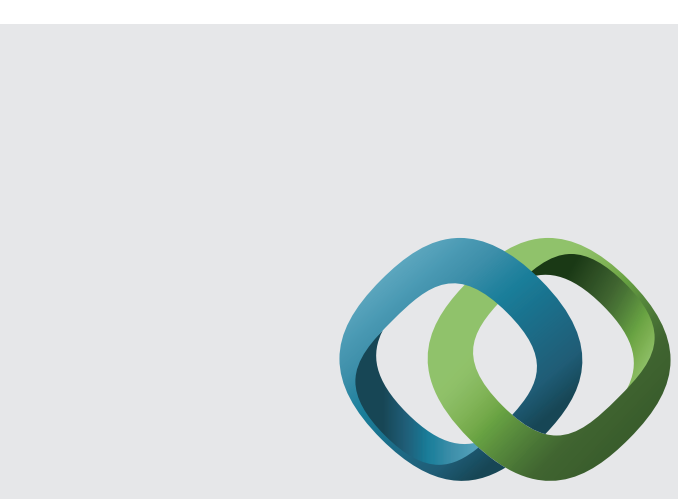

\section{Hindawi}

Submit your manuscripts at

http://www.hindawi.com
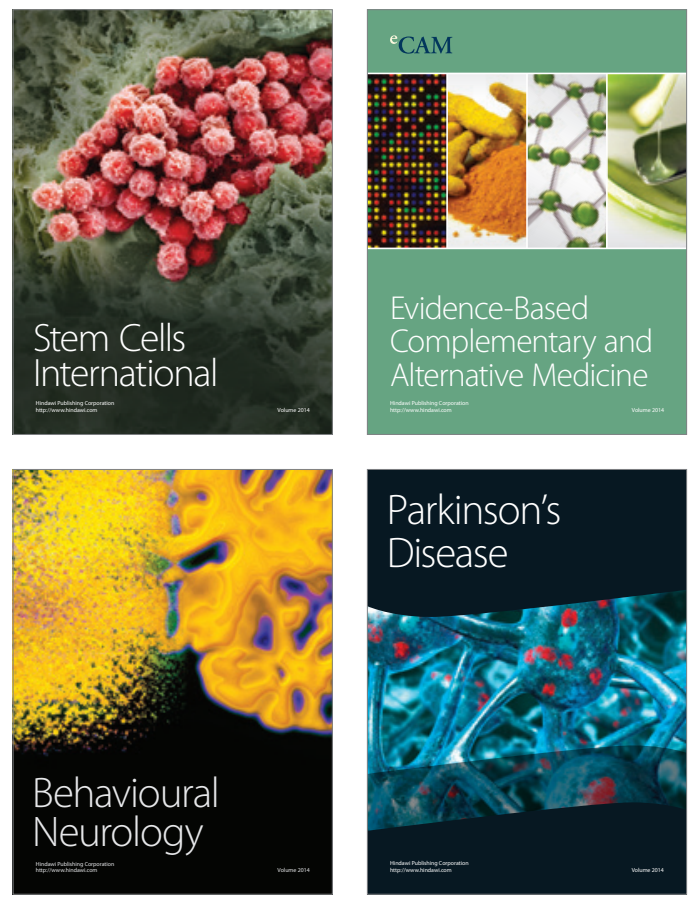
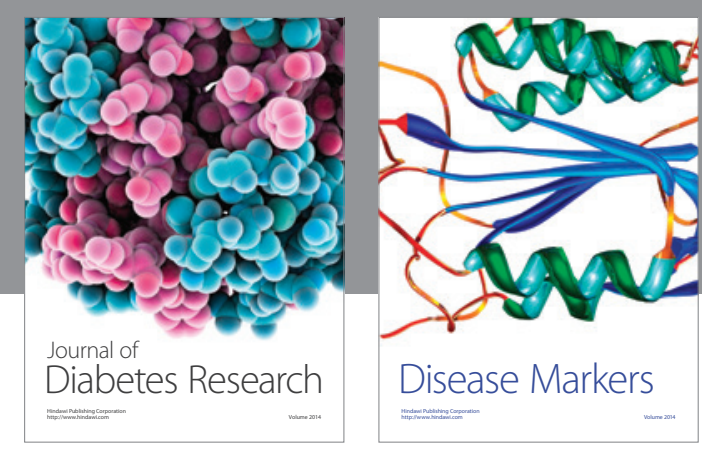

Disease Markers
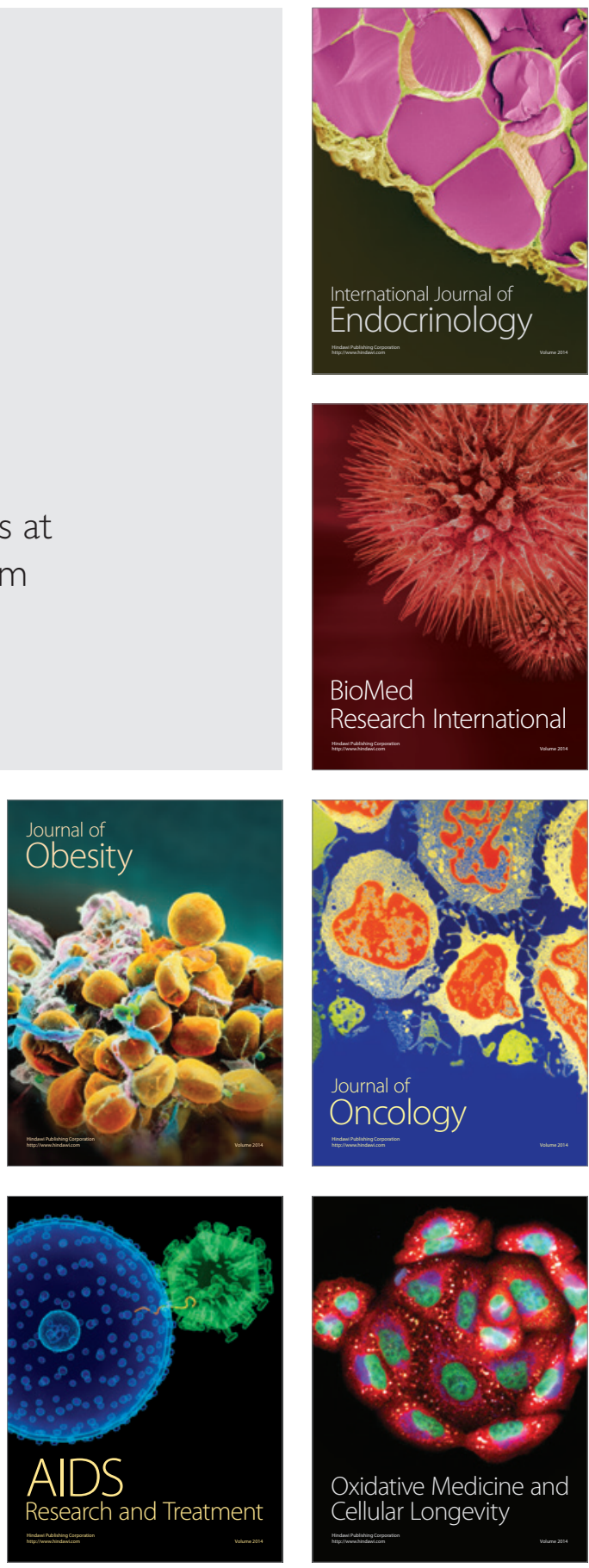